\title{
Efficacy and safety of guaifenesin for upper back, neck, and shoulder pain: a Phase II proof-of- concept, multicenter, placebo-controlled, repeat-dose, parallel-group study
}

\author{
This article was published in the following Dove Press journal: \\ Journal of Pain Research \\ 21 March 2017 \\ Number of times this article has been viewed
}

\author{
Agron Collaku \\ Yong Yue \\ Kenneth Reed \\ GlaxoSmithKline Consumer \\ Healthcare, Parsippany, NJ, USA
}

Correspondence: Agron Collaku 8 Campus Drive, Parsippany, NJ 07054, USA

Tel +l 9734902102

Email agron.collaku@perrigo.com
Background/objective: Guaifenesin, an over-the-counter (OTC) expectorant, has exhibited muscle relaxant effects preclinically and clinically. This proof-of-principle study explored whether OTC doses of guaifenesin can provide relief from acute upper back, neck, or shoulder muscle spasm and pain.

Methods: This multicenter, placebo-controlled, repeat-dose, parallel study randomly assigned adults experiencing acute pain and muscle spasm in their upper back, neck, or shoulder to guaifenesin 600 or $1200 \mathrm{mg}$ or matched placebo twice daily (BID) in a 2:2:1:1 ratio for 7 days. The primary end point was the change from baseline in muscle spasm relief, measured using an 11 -point numeric rating scale $(0=$ not present to $10=$ unbearable) recorded twice daily and averaged over the 7-day treatment period. Analyses were performed using a linear mixed model that included treatment as a fixed effect and site as a random effect.

Results: A total of 77 subjects were included in the 4 treatment groups. Least squares mean muscle spasm score over 7 days was 1.77 with guaifenesin $1200 \mathrm{mg}, 1.42$ with its matched placebo, 1.53 with guaifenesin $600 \mathrm{mg}$, and 1.74 with its matched placebo. Treatment with guaifenesin $1200 \mathrm{mg}$ BID provided $25 \%$ greater reduction in mean muscle spasm over its matched placebo and 16\% greater reduction than guaifenesin $600 \mathrm{mg}$ BID. These differences were not statistically significant. Based on comparisons of absolute mean values, a consistent directional change in effect was observed, suggesting some benefit from placebo to lower-to-upper doses of guaifenesin with regard to muscle spasm, tension, pain, discomfort, and relaxation. No severe or serious adverse events were reported.

Conclusion: Results suggest the potential for OTC dose of guaifenesin $1200 \mathrm{mg}$ BID to provide symptomatic relief of upper back musculoskeletal pain and spasm. Confirmation of this preliminary result in a larger, adequately powered study is needed.

Keywords: guaifenesin, upper back pain, muscle spasm, muscle relaxation, Vernon-Mior disability assessment

\section{Introduction}

Musculoskeletal disorders of the upper back, shoulders, and neck are common in many occupations that require physical exertion, repetitive movements, static muscle contraction, prolonged sitting before a computer, or maintaining fixed or extreme postures. ${ }^{1-6}$ In some instances, muscle fatigue subsequent to overwork or to poor posture results in tension or overactivation of the muscles of the neck. ${ }^{2,5,7,8}$ Work-related neck, shoulder, and upper back musculoskeletal disorders include tension neck syndrome, rotator 
cuff syndrome, upper back pain, and shoulder tendonitis or tenosynovitis. ${ }^{9-12}$ These conditions may cause deterioration of joints, muscles, and soft tissue, persistent pain in related body areas, and disability. ${ }^{6}$

Workplace interventions (eg, resistance training, stretching exercise programs) may help to prevent and manage musculoskeletal disorders. ${ }^{13}$ In addition, pharmacologic options, such as acetaminophen and nonsteroidal anti-inflammatory drugs (NSAIDs), are used to manage musculoskeletal pain, and muscle relaxants may be used to manage muscle pain, stiffness, and spasm. ${ }^{14-17}$ Although there are many skeletal muscle relaxants, systemically active products are generally available with prescription and are associated with welldocumented adverse effects such as somnolence, dizziness, weakness, and dry mouth. ${ }^{17}$

Guaifenesin, an over-the-counter (OTC) expectorant, has exhibited a muscle relaxant effect in preclinical studies and in patients with cerebral palsy when used in doses higher than those currently available for OTC use. ${ }^{18,19}$ In other preclinical investigations, guaifenesin has shown modest but significant analgesic and anti-inflammatory effects. ${ }^{20}$ Little is known about the potential mechanism by which guaifenesin produces these effects, but a chemically similar muscle relaxant, mephenesin, has been found to be an antagonist of the excitatory amino acids $N$-methyl-D-aspartate (NMDA) and $\alpha$-amino-3-hydroxy-5-methyl-4-isoxazolepropionic acid (AMPA). ${ }^{18,21}$ Whether a true muscle relaxant effect occurs at OTC doses of guaifenesin has not been studied previously. The primary objective of this proof-of-principle study was to explore the efficacy and safety of 2 OTC dose strengths of guaifenesin compared with matched placebos for symptom relief in subjects with acute upper back, neck, or shoulder muscle spasm and pain.

\section{Methods}

\section{Study design and procedures}

This multicenter, randomized, placebo-controlled, repeatdose, 4-arm, parallel study was conducted at 4 investigational sites in the United States (clinicaltrials.gov identifier: NCT01562548). Eligible subjects with upper back, neck, or shoulder muscle spasm and pain were randomly assigned in a 2:2:1:1 ratio to receive guaifenesin $600 \mathrm{mg}$ (a single 600 mg Mucinex ${ }^{\circledR}$ Extended Release Bi-layer Tablet; Reckitt Benckiser, Parsippany, NJ, USA), guaifenesin $1200 \mathrm{mg}$ (two 600 mg Mucinex ${ }^{\circledR}$ Extended Release tablets), placebo matched to guaifenesin $600 \mathrm{mg}$ (ie, 1 placebo tablet, hereafter referred to as placebo-600), or placebo matched to guaifenesin $1200 \mathrm{mg}$ (ie, 2 placebo tablets, hereafter referred to as placebo-1200). The randomization schedule was generated by the Biostatistics Department of GlaxoSmithKline Consumer Healthcare (Parsippany, NJ, USA). All doses were self-administered twice daily (BID) for 7 consecutive days.

Subjects recorded the intensity of upper back, neck, or shoulder muscle spasm, stiffness, tension, pain, and discomfort twice daily ( 8 am and $8 \mathrm{pm}$ ) on a diary card, using an 11-point numeric rating scale (NRS) for each symptom, with anchors of $0=$ symptom not present and $10=$ unbearable symptoms. On days 4 and 7, investigators telephoned subjects to evaluate muscle relaxation and to perform a global assessment of treatment helpfulness (GATH), sleep disturbance (GASD), and headache frequency/intensity (GAHF/GAHI). At that time, the investigator also completed the Vernon-Mior disability questionnaire. Muscle relaxation was scored on a 5-point categorical scale of $0=$ no relaxation, $1=$ a little relaxation, $2=$ fair relaxation, $3=$ good relaxation, and $4=$ complete relaxation. The GATH was scored on a scale of $0=$ poor, $1=$ fair, $2=$ good, $3=$ very good, and $4=$ excellent. The GASD, GAHF, and GAHI recorded whether the symptom had increased, decreased, or remained the same. The Vernon-Mior disability questionnaire was originally designed to assess how neck pain affects everyday life with regard to pain intensity, personal care, lifting, reading, headaches, concentration, work, driving, sleeping, and recreation, with each item rated on a 6-point scale, with 1 being no disability and 6 being complete disability. Here, the same questionnaire was used to measure disability resulting from neck, upper back, and shoulder pain.

This study, which was conducted from February 2012 through May 2013, conformed to the principles of the Declaration of Helsinki and was approved by an Institutional Review Board (Quorum Review, Inc, Seattle, WA, USA). Eligible subjects provided written informed consent prior to study participation.

\section{Study population}

Subjects enrolled in the study were healthy men and women aged 18-65 years with a new episode of acute upper back, neck, or shoulder muscle spasm and pain. Inclusion criteria were muscle pain and/or spasm with an onset within 48 hours of randomization and at least 30 days since a previous episode; symptoms consistent with a clinical diagnosis; and subject-rated muscle spasm and pain scores of at least $40 \mathrm{~mm}$ on a $100 \mathrm{~mm}$ visual analog scale. Subjects had to have a normal neurologic evaluation, physical examination, and clinical laboratory test results. Women of childbearing potential had to be practicing a reliable method of contraception. 
Exclusion criteria were current or recent history of neck, back, and/or shoulder injuries; spinal disk disease; osteoporosis; liver and/or kidney disease; myocardial infarction within 12 months of randomization; history of upper back pain with active hypersensitive spots; history of other chronic pain (eg, headache, osteoarthritis, or lower back pain); and known or suspected intolerance or hypersensitivity to guaifenesin or methocarbamol (or closely related compounds) or any other study medication ingredient. Individuals who had used muscle relaxants, narcotics, monoamine oxidase inhibitors, or selegiline within 2 weeks of randomization or who were currently using tricyclic antidepressants, lithium, anticoagulants, or tramadol were ineligible. Additional exclusion criteria were current pregnancy or breastfeeding, drug or alcohol abuse within the previous 2 years, use of an investigational drug or participation in another clinical trial within 30 days prior to randomization, and involvement in a worker's compensation case. Subjects had to agree to refrain from use of analgesics (including NSAIDs, with the exception of aspirin $\leq 325 \mathrm{mg}$ / day), muscle relaxants, physical or massage therapy, acupuncture, and heat and spa treatments for the duration of the study.

\section{Efficacy end points}

The primary efficacy end point was the change in muscle spasm over the 7-day study period, measured as mean change from baseline for both morning and evening spasms in the 11-point NRS scores recorded in the subjects' diary cards and averaged over the 7-day treatment period. Secondary efficacy end points included change from baseline in muscle stiffness, tension, pain, discomfort, and relaxation over the 7-day period, measured as mean change from baseline for both morning and evening symptoms on the 11-point NRS scores. Other secondary end points included muscle relaxation scores, as well as scores for GATH and the individual Vernon-Mior disability questionnaire components on days 4 and 7.

\section{Safety}

Safety assessments included treatment-emergent adverse events (TEAEs) and serious adverse events (SAEs). Safety was monitored from the start of treatment until 7 days after the last treatment administration, and treatment-related SAEs were reported from the time of informed consent through all follow-up contact. Severity and relationship to treatment were assessed for all TEAEs.

\section{Statistical analyses}

Given the proof-of-concept objective, no formal sample size calculations were performed. A total of 78 subjects
(26 in each active treatment randomization group and 13 in each placebo randomization group) were considered sufficient to visualize any directional change in increased efficacy from placebo to lower- and upper-dose guaifenesin groups for muscle spasm, stiffness, tension, pain, discomfort, and relaxation scores. Directional changes in efficacy were based primarily on comparisons of absolute values of means of guaifenesin $1200 \mathrm{mg}$ BID with placebo-1200 and with guaifenesin $600 \mathrm{mg}$ BID. Placebo-600 was not included in these comparisons, as its only purpose was to test the effect of guaifenesin $600 \mathrm{mg}$ BID. Statistical testing to detect significant differences between treatments was exploratory, as no formal sample size calculations were done for this study.

The safety population consisted of all subjects who were randomized and received any treatment. Efficacy analyses were conducted on the intent-to-treat (ITT) population, which was defined as subjects who had received at least 1 dose of study medication and who had at least 1 post-baseline efficacy assessment.

All primary and secondary end points were summarized using descriptive statistics (mean, standard deviation [SD], minimum, maximum) in order to provide an absolute comparison between treatments for the purpose of identifying a directional change in efficacy. In addition, a mixed-model analysis of covariance (ANCOVA; Proc Mixed of SAS) was used to analyze changes from baseline in subject NRS ratings over the 7-day period (ie, mean of each morning's and evening's changes from baseline on days 1-7). A similar mixed model was used to assess mean muscle relaxation and GATH scores on days 4 and 7 (incorporating morning and evening scores). Both ANCOVA models included factors for treatment (fixed effect), site (random effect), and baseline assessment of the end point being analyzed as a covariate. Treatment differences were presented with 95\% confidence intervals and associated $P$-values. Global assessments (GASD, GAHF, and GAHI) were summarized by percentage of subjects recording that symptoms had increased, decreased, or stayed the same. Vernon-Mior components and overall mean scores were summarized using descriptive statistics. All statistical testing was two-sided at the $5 \%$ significance level. No imputation was performed for missing values for any of the assessments, and subjects who dropped out or were excluded were included in all analyses for which they were evaluable.

Adverse events were classified using the Medical Dictionary for Drug Regulatory Activities version 15.1 and summarized using descriptive statistics. 


\section{Results}

\section{Study population}

Ninety-five people were screened, of whom 79 met the enrollment criteria and were randomly assigned to receive guaifenesin $600 \mathrm{mg}$ BID ( $\mathrm{n}=25)$, guaifenesin $1200 \mathrm{mg}$ BID $(n=25)$, placebo-600 $(n=15)$, and placebo-1200 $(n=14)$. One subject in the guaifenesin $1200 \mathrm{mg}$ BID group was lost to follow-up and did not receive treatment and was excluded from the safety and ITT populations. One subject in the placebo-1200 group was excluded from the ITT population because the number of pills returned at the end of the study indicated a much lower adherence to study procedures than that indicated in the subject's diary records. Thus, 78 subjects were included in the safety population and 77 in the ITT population.

The overall mean $( \pm \mathrm{SD})$ age of randomized subjects was 45.9 (11.5) years, and slightly more than half of all subjects were males $(55.1 \%)$. Most study subjects were White (66.7\%); the remaining subjects were primarily Black (32.1\%). The demographics of the subjects in the individual treatment arms are shown in Table 1.

\section{Muscle spasm relief}

Over the 7-day study period, the guaifenesin $1200 \mathrm{mg}$ BID group showed a potential directional change for a greater effect on decreasing muscle spasm compared with its matched placebo and guaifenesin $600 \mathrm{mg}$ BID (Figure 1A). Reduction of muscle spasm in subjects treated with guaifenesin $1200 \mathrm{mg}$ BID was $25 \%$ greater than that of subjects in the placebo-1200 group and $16 \%$ greater than that of subjects in the guaifenesin $600 \mathrm{mg}$ BID group. However, these differences were not statistically significant (Table 2). Guaifenesin $600 \mathrm{mg}$ BID did not show a clear effect on decreasing muscle spasm compared with its matched placebo (mean change score, 1.53 vs 1.74; Table 2).

\section{Change in relief of other symptoms}

Over the 7-day study period, treatment with guaifenesin $1200 \mathrm{mg}$ BID provided numerically greater improvements than its matched placebo and guaifenesin $600 \mathrm{mg}$ BID on most other subject-reported symptoms, including pain (Figure 1B), tension (Figure 1C), and discomfort. Subjects in the guaifenesin $1200 \mathrm{mg}$ BID group experienced greater mean reductions of $52 \%$ and $31 \%$ in pain, $28 \%$ and $13 \%$ in tension, and $108 \%$ and $20 \%$ in discomfort compared with subjects in the placebo-1200 and guaifenesin $600 \mathrm{mg}$ BID groups, respectively (Table 2). Guaifenesin $600 \mathrm{mg}$ BID did not show a clear effect toward improvement on these outcomes compared with its matched placebo. Improvement in muscle discomfort with guaifenesin $1200 \mathrm{mg}$ BID was significantly greater than placebo-1200 $(P=0.0358)$. All other differences among treatments for the above-mentioned end points were not significant ( $P>0.05$; Table 2$)$.

There was a directional change suggesting increasing effects on muscle relaxation from placebo-1200 to guaifenesin $600 \mathrm{mg}$ BID to guaifenesin $1200 \mathrm{mg}$ BID (Table 3). Mean muscle relaxation on day 4 for subjects in the guaifenesin $1200 \mathrm{mg}$ BID group was 39\% and 3\% greater than mean muscle relaxation for subjects in the placebo-1200 and guaifenesin $600 \mathrm{mg}$ BID groups, respectively. On day 7, this directional change continued with a $28 \%$ and $17 \%$ greater effect of guaifenesin $1200 \mathrm{mg}$ BID over placebo-1200 and guaifenesin $600 \mathrm{mg}$ BID groups, respectively. Guaifenesin $600 \mathrm{mg}$ BID did not produce greater muscle relaxation compared with its matched placebo on both days 4 and 7 (Table 3). Similar results to muscle relaxation were observed for GATH (Table 3). On day 4, subjects rated guaifenesin $1200 \mathrm{mg}$ BID $94 \%$ and $10 \%$ higher than subjects in the placebo-1200 and guaifenesin $600 \mathrm{mg}$ BID groups, respectively. On day 7 , these values were $23 \%$ and $10 \%$, respectively.

Table I Demographic characteristics (safety population)

\begin{tabular}{|c|c|c|c|c|}
\hline Characteristics & $\begin{array}{l}\text { Guaifenesin } 600 \mathrm{mg} \text { BID } \\
(\mathrm{n}=25)\end{array}$ & $\begin{array}{l}\text { Placebo-600 } \\
(n=15)\end{array}$ & $\begin{array}{l}\text { Guaifenesin I } 200 \mathrm{mg} \text { BID } \\
(\mathrm{n}=24)\end{array}$ & $\begin{array}{l}\text { Placebo- } 1200 \\
(n=14)\end{array}$ \\
\hline Age, mean (SD), years & $47.2(11.87)$ & $43.8(10.35)$ & $45.3(10.62)$ & $47.3(13.92)$ \\
\hline \multicolumn{5}{|l|}{ Sex, n (\%) } \\
\hline Male & $17(68)$ & $6(40)$ & $12(50)$ & $8(57.1)$ \\
\hline Female & $8(32)$ & $9(60)$ & $12(50)$ & $6(42.9)$ \\
\hline \multicolumn{5}{|l|}{ Race, n (\%) } \\
\hline White & $17(68)$ & II (73.3) & $13(54.2)$ & II (78.6) \\
\hline Black/African American & $8(32)$ & $4(26.7)$ & II (45.8) & $2(14.3)$ \\
\hline Multiple & 0 & 0 & 0 & I (7.I) \\
\hline
\end{tabular}

Notes: BID, twice daily; placebo-600, placebo matched to guaifenesin $600 \mathrm{mg}$ BID; placebo-1200, placebo matched to guaifenesin I200 mg BID. Abbreviation: SD, standard deviation. 

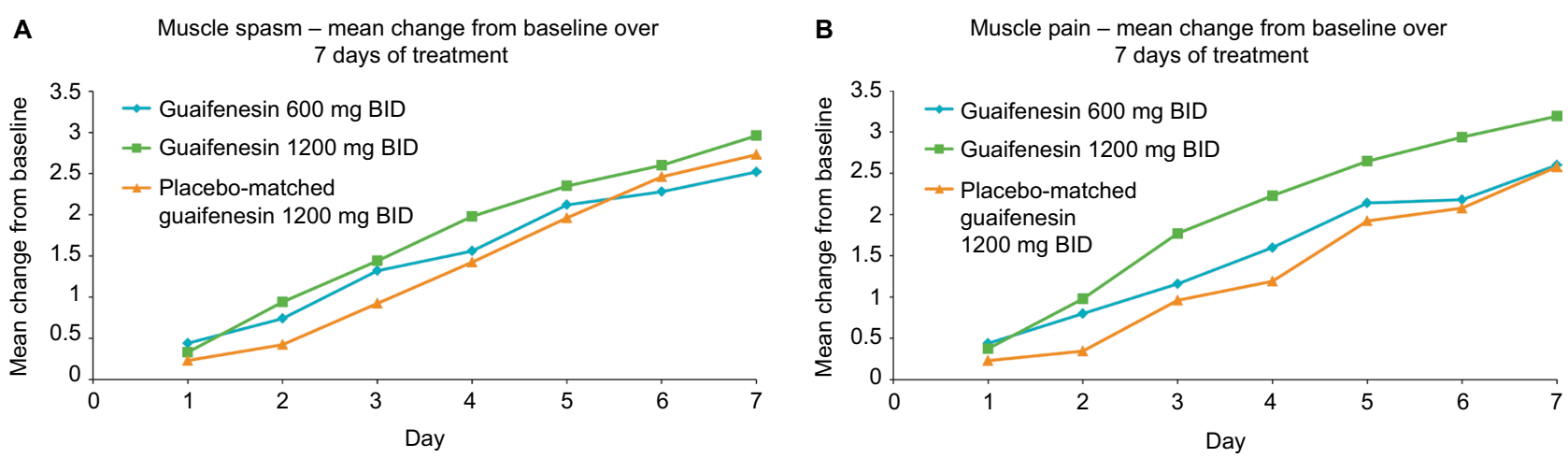

C Muscle tension - mean change from baseline over

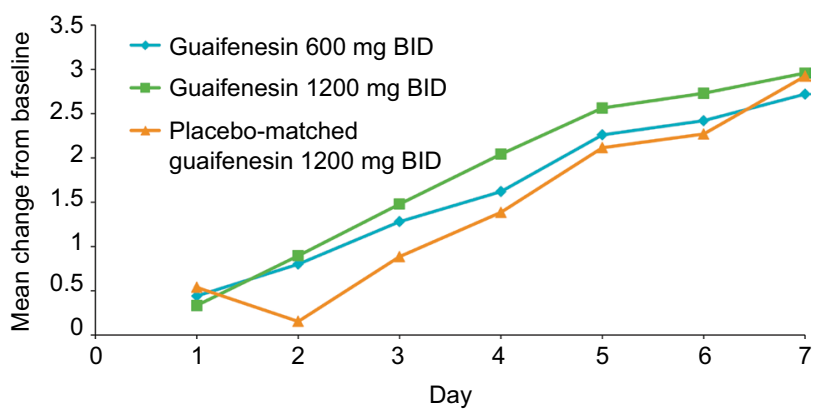

Figure I Mean change from baseline through 7 days in (A) muscle spasm NRS scores ${ }^{\mathrm{a}}$, (B) muscle pain NRS scores, and (C) muscle tension NRS scores with guaifenesin $600 \mathrm{mg}$ BID, guaifenesin $1200 \mathrm{mg}$ BID, and placebo- 200 (ITT population).

Notes: Placebo-600 was not included in these directional change comparisons, as its only purpose was to test the effect of guaifenesin 600 mg BID. ${ }^{a} A$ positive difference is favorable, with greater changes from baseline NRS scores indicating greater improvement in symptoms. BID, twice daily; placebo-I200, placebo matched to guaifenesin $1200 \mathrm{mg}$ BID.

Abbreviations: ITT, intent-to-treat; NRS, numeric rating scale.

The greatest treatment effect for GATH and muscle relaxation was observed on day 4 (Table 3 ). There was a significant difference between guaifenesin $1200 \mathrm{mg}$ BID and placebo-1200 $(P=0.0211)$ for GATH and a borderline significant difference between these 2 groups for muscle relaxation $(P=0.0523)$. On day 7 , treatment effect increased compared with day 4 . For example, the effect of guaifenesin $1200 \mathrm{mg}$ BID on muscle relaxation on day 7 was $22 \%$ higher than on day 4.

There were no directional changes in effect with regard to effects on sleep disturbance, headache frequency, or headache intensity based on GASD, GAHF, and GAHI scores, respectively (Table S1 for day 7 data).

\section{Vernon-Mior disability questionnaire}

On day 4, subjects in the guaifenesin $1200 \mathrm{mg}$ BID group had overall better (lower) mean Vernon-Mior index scores than subjects in the guaifenesin $600 \mathrm{mg}$ BID group, and subjects in the guaifenesin $600 \mathrm{mg}$ BID group had overall better (lower) scores than subjects in the placebo- 1200 group (Figure 2). There was a directional change on day 4 of placebo-1200 (2.39) > guaifenesin $600 \mathrm{mg}$ BID (2.31) > guaifenesin $1200 \mathrm{mg}$ BID (2.01). There was a reduction of $16 \%$ and $13 \%$ in the overall mean Vernon-Mior index for subjects in the guaifenesin $1200 \mathrm{mg}$ BID group compared with subjects in the placebo- 1200 and guaifenesin $600 \mathrm{mg}$ BID groups. A similar directional change was observed on day 7 , where there was a reduction of $10 \%$ and $20 \%$ in the overall Vernon-Mior index of subjects in the guaifenesin $1200 \mathrm{mg}$ BID group compared with the placebo-1200 and guaifenesin $600 \mathrm{mg}$ BID groups, respectively. Within each treatment group, Vernon-Mior disability scores improved noticeably from day 4 to day 7 (Figure 2). A summary of results for upper back/neck/shoulder pain disability end points is presented in Table 4.

\section{Safety outcomes}

Twenty-one TEAEs were reported by 17 (21.8\%) subjects in the study. Eight TEAEs occurred in 6 subjects $(25.0 \%)$ in the guaifenesin $1200 \mathrm{mg}$ BID group, 4 TEAEs in 3 subjects $(21.4 \%)$ in the placebo-1200 group, 8 TEAEs in 7 subjects $(28.0 \%)$ in the guaifenesin $600 \mathrm{mg}$ BID group, and $1 \mathrm{TEAE}$ 
Table 2 Mean change from baseline in subject-reported muscle symptom NRS scores ${ }^{\mathrm{a}}$ during 7 days of treatment (ITT population)

\begin{tabular}{|c|c|c|c|c|c|}
\hline Parameters & $\begin{array}{l}\text { Guaifenesin } 600 \mathrm{mg} \\
\text { BID }(n=25)\end{array}$ & $\begin{array}{l}\text { Placebo-600 } \\
(n=15)\end{array}$ & \multirow[t]{2}{*}{$\begin{array}{l}\text { Guaifenesin } \\
\text { I } 200 \mathrm{mg} \\
\text { BID }(n=24)\end{array}$} & $\begin{array}{l}\text { Placebo- } 1200 \\
(n=13)\end{array}$ & $\begin{array}{l}\text { Guaifenesin I } 200 \mathrm{mg} \text { BID vs } \\
\text { guaifenesin } 600 \mathrm{mg} \text { BID }\end{array}$ \\
\hline \multicolumn{5}{|l|}{ Spasm (primary end point) } & \\
\hline Baseline, mean (SD) & $5.48(2.16)$ & $5.27(1.94)$ & $5.38(1.69)$ & $5.46(2.26)$ & \\
\hline Days I-7, mean (SD) & $3.94(1.86)$ & $3.55(1.76)$ & $3.60(1.93)$ & $4.03(1.91)$ & \\
\hline \multicolumn{6}{|l|}{ Change from baseline } \\
\hline LS mean ${ }^{\mathrm{b}}$ & 1.53 & 1.74 & 1.77 & 1.42 & \\
\hline $95 \% \mathrm{Cl}$ & \multicolumn{2}{|c|}{-1.23 to 0.80} & \multicolumn{2}{|c|}{-0.72 to 1.42} & -0.64 to 1.13 \\
\hline$P$-value & \multicolumn{2}{|c|}{0.6784} & \multicolumn{2}{|c|}{0.5195} & 0.5843 \\
\hline \multicolumn{6}{|l|}{ Stiffness } \\
\hline Baseline, mean (SD) & $6.24(1.09)$ & $6.07(1.83)$ & $5.46(1.28)$ & $5.85(1.68)$ & \\
\hline Days I-7, mean (SD) & $4.48(1.44)$ & $4.14(1.75)$ & $3.72(1.68)$ & $4.20(1.62)$ & \\
\hline \multicolumn{6}{|l|}{ Change from baseline } \\
\hline LS mean ${ }^{\mathrm{b}}$ & 1.85 & 2.05 & 1.82 & 1.72 & \\
\hline $95 \% \mathrm{Cl}$ & \multicolumn{2}{|c|}{-1.18 to 0.78} & \multicolumn{2}{|c|}{-0.94 to 1.13} & -0.89 to 0.83 \\
\hline$P$-value & \multicolumn{2}{|c|}{0.6892} & \multicolumn{2}{|c|}{0.8562} & 0.9394 \\
\hline \multicolumn{6}{|l|}{ Tension } \\
\hline Baseline, mean (SD) & $6.00(1.47)$ & $5.80(1.78)$ & $5.67(1.37)$ & $5.77(2.24)$ & \\
\hline Days I-7, mean (SD) & $4.38(1.46)$ & $3.97(I .7 I)$ & $3.84(1.73)$ & $4.34(1.33)$ & \\
\hline \multicolumn{6}{|l|}{ Change from baseline } \\
\hline LS mean ${ }^{b}$ & 1.69 & 1.94 & 1.91 & 1.49 & \\
\hline $95 \% \mathrm{Cl}$ & \multicolumn{2}{|c|}{-1.29 to 0.80} & \multicolumn{2}{|c|}{-0.68 to 1.52} & -0.69 to 1.14 \\
\hline$P$-value & \multicolumn{2}{|c|}{0.6422} & \multicolumn{2}{|c|}{0.4493} & 0.6322 \\
\hline \multicolumn{6}{|l|}{ Pain } \\
\hline Baseline, mean (SD) & 6.04 (I.59) & $6.40(1.45)$ & $5.83(\mathrm{I} .0 \mathrm{I})$ & $5.31(2.14)$ & \\
\hline Days I-7, mean (SD) & $4.51(1.53)$ & $4.18(1.59)$ & $3.85(1.69)$ & $3.99(1.78)$ & \\
\hline \multicolumn{6}{|l|}{ Change from baseline } \\
\hline LS mean ${ }^{\mathrm{b}}$ & 1.59 & 2.35 & 2.07 & 1.36 & \\
\hline $95 \% \mathrm{Cl}$ & \multicolumn{2}{|c|}{-1.81 to 0.28} & \multicolumn{2}{|c|}{-0.39 to 1.82} & -0.43 to 1.40 \\
\hline$P$-value & 0.1493 & & & 007 & 0.2924 \\
\hline Discomfort & & & & & \\
\hline Baseline, mean (SD) & $6.44(1.50)$ & $6.73(1.44)$ & $6.08(1.38)$ & $5.31(2.25)$ & \\
\hline Days I-7, mean (SD) & $4.63(1.55)$ & $4.36(1.5 I)$ & $3.92(1.72)$ & $4.27(\mathrm{I} .5 \mathrm{I})$ & \\
\hline Change from baseline & & & & & \\
\hline LS mean ${ }^{\mathrm{b}}$ & 1.95 & 2.57 & 2.33 & 1.12 & \\
\hline $95 \% \mathrm{Cl}$ & -1.69 to & & & 2.34 & -0.56 to 1.31 \\
\hline$P$-value & 0.250 & & & 358 & 0.4227 \\
\hline
\end{tabular}

Notes: ${ }^{a} \mathrm{~A}$ positive difference is favorable, with greater changes from baseline NRS scores indicating greater improvement in symptoms. ${ }^{\mathrm{b}} \mathrm{Least}$ squares mean of the differences between the baseline NRS assessment and each morning and evening NRS score during the 7-day treatment period, based on mixed model ANCOVA with treatment as fixed effect and site as random effect. BID, twice daily; placebo-600, placebo matched to guaifenesin 600 mg BID; placebo- I200, placebo matched to guaifenesin I200 mg BID. Abbreviations: ANCOVA, analysis of covariance; Cl, confidence interval; ITT, intent-to-treat; LS, least squares; NRS, numeric rating scale; SD, standard deviation.

in 1 subject (6.7\%) in the placebo-600 group. The most common categories of TEAEs were nervous system disorders (eg, headache, dizziness, dysgeusia, and somnolence) and infections (eg, upper respiratory infections and nasopharyngitis). Nearly all TEAEs were mild; there were 2 moderate TEAEs (upper respiratory tract infection and hyperhidrosis) in the guaifenesin $1200 \mathrm{mg}$ BID group, 3 moderate TEAEs (headache, sinusitis, and sleep disorder) in the placebo-1200 group, 2 moderate TEAEs (headache and arthralgia) in the guaifenesin $600 \mathrm{mg}$ BID group, and no moderate TEAEs in the placebo-600 group. No severe TEAEs were reported in any group. Seven TEAEs in 7 subjects were considered to be treatment-related, including 1 case of moderate hyperhidrosis in the guaifenesin $1200 \mathrm{mg}$ BID group, 1 moderate headache and 1 moderate sleep disorder in the placebo-1200 group, 1 mild case each of dizziness, dysgeusia, and fatigue in the guaifenesin $600 \mathrm{mg}$ BID group, and 1 case of mild abdominal discomfort in the placebo-600 group. All AEs resolved, and no SAEs or discontinuations attributable to AEs were reported.

\section{Discussion}

This is the first study to evaluate guaifenesin for managing symptoms of upper back, neck, and shoulder pain. The results 
Table 3 Muscle relaxation scores and GATH (ITT population)

\begin{tabular}{|c|c|c|c|c|c|}
\hline Parameters & $\begin{array}{l}\text { Guaifenesin } 600 \mathrm{mg} \\
\text { BID }(n=25)\end{array}$ & \multirow[t]{2}{*}{$\begin{array}{l}\text { Placebo-600 } \\
(n=15)\end{array}$} & $\begin{array}{l}\text { Guaifenesin I } 200 \mathrm{mg} \\
\text { BID }(\mathrm{n}=24)\end{array}$ & \multirow[t]{2}{*}{$\begin{array}{l}\text { Placebo- } 1200 \\
(n=13)\end{array}$} & \multirow[t]{2}{*}{$\begin{array}{l}\text { Guaifenesin I } 200 \mathrm{mg} \text { BID } \\
\text { vs guaifenesin } 600 \mathrm{mg} \text { BID }\end{array}$} \\
\hline Muscle relaxat & rating, day 4 & & & & \\
\hline LS mean ${ }^{\mathrm{a}}$ & 1.73 & 1.83 & 1.78 & 1.28 & \\
\hline $95 \% \mathrm{Cl}$ & \multicolumn{2}{|c|}{-0.58 to 0.37} & \multicolumn{2}{|c|}{-0.01 to 1.00} & -0.36 to 0.47 \\
\hline$P$-value & \multicolumn{2}{|c|}{0.6656} & \multicolumn{2}{|c|}{0.0523} & 0.7964 \\
\hline \multicolumn{6}{|c|}{ Muscle relaxation rating, day 7} \\
\hline LS mean ${ }^{\mathrm{a}}$ & 1.86 & 2.27 & 2.17 & 1.69 & \\
\hline $95 \% \mathrm{Cl}$ & \multicolumn{2}{|c|}{-1.05 to 0.23} & \multicolumn{2}{|c|}{-0.20 to 1.15} & -0.25 to 0.87 \\
\hline$P$-value & \multicolumn{2}{|c|}{0.2087} & \multicolumn{2}{|c|}{0.1648} & 0.2779 \\
\hline \multicolumn{6}{|l|}{ GATH, day 4} \\
\hline LS mean ${ }^{\mathrm{b}}$ & $\mathrm{I} .47$ & 1.52 & 1.61 & 0.83 & \\
\hline $95 \% \mathrm{Cl}$ & \multicolumn{2}{|c|}{-0.68 to 0.57} & \multicolumn{2}{|c|}{0.12 to 1.43} & -0.40 to 0.69 \\
\hline$P$-value & \multicolumn{2}{|c|}{0.8657} & \multicolumn{2}{|c|}{0.0211} & 0.5979 \\
\hline \multicolumn{6}{|l|}{ GATH, day 7} \\
\hline LS mean ${ }^{\mathrm{b}}$ & 1.55 & 1.72 & 1.70 & 1.37 & \\
\hline $95 \% \mathrm{Cl}$ & \multicolumn{2}{|c|}{-0.87 to 0.53} & \multicolumn{2}{|c|}{-0.41 to 1.06} & -0.46 to 0.76 \\
\hline$P$-value & \multicolumn{2}{|c|}{0.6278} & \multicolumn{2}{|c|}{0.3847} & 0.6283 \\
\hline
\end{tabular}

Notes: aLS mean muscle relaxation score based on mixed model ANCOVA with treatment as fixed effect, site as random effect, and baseline muscle spasm intensity as covariate. Muscle relaxation was scored on a scale of $0=$ no relaxation, $I=$ a little relaxation, $2=$ fair relaxation, $3=$ good relaxation, and $4=$ complete relaxation. ${ }^{b} \mathrm{LS}$ mean GATH score, based on a scale of $0=$ poor, $\mathrm{I}=$ fair, 2 = good, $3=$ very good, and $4=$ excellent. BID, twice daily; placebo-600, placebo matched to guaifenesin 600 mg BID; placebo-1200, placebo matched to guaifenesin $1200 \mathrm{mg}$ BID.

Abbreviations: ANCOVA, analysis of covariance; CI, confidence interval; ITT, intent-to-treat; LS, least squares; GATH, global assessment of treatment helpfulness.

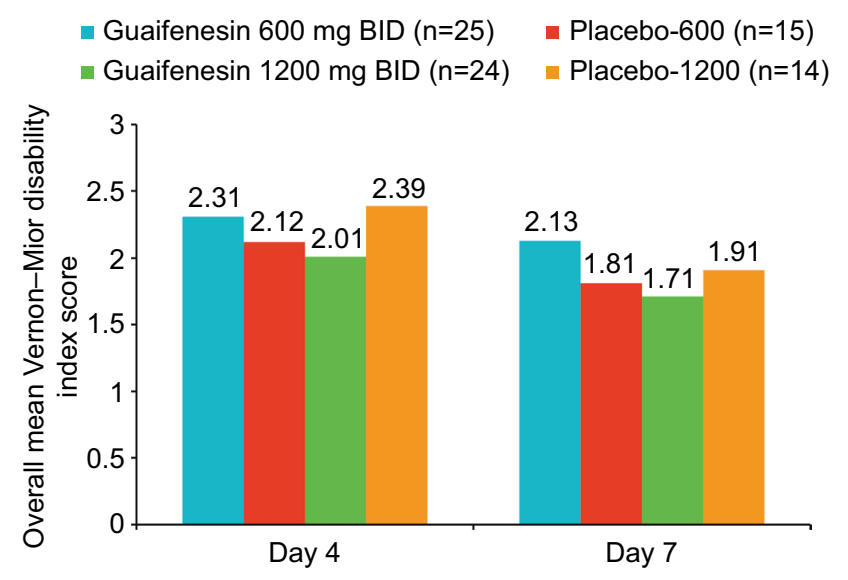

Figure 2 Overall mean Vernon-Mior disability index scores at days 4 and 7 (ITT population).

Notes: BID, twice daily; placebo-600, placebo matched to guaifenesin $600 \mathrm{mg}$ BID; placebo-1200, placebo matched to guaifenesin $1200 \mathrm{mg}$ BID.

Abbreviation: ITT, intent-to-treat.

suggest further investigation of the potential of guaifenesin $1200 \mathrm{mg}$ BID to provide some relief in muscle spasm, pain, tension, and discomfort of the upper back, neck, and shoulders is warranted. The reduction in muscle discomfort with guaifenesin $1200 \mathrm{mg}$ compared with placebo- 1200 was statistically significant $(P=0.0358)$; the rest of these improvements were not significant $(P>0.05)$; it is noted that in this small proof-of-principle study, analyses were not powered for pre-specified statistical testing between treatments. The $1200 \mathrm{mg}$ BID dose of guaifenesin suggested a potential for therapeutic muscle relaxant effect. However, any observed differences between treatments diminished over the course of the study, possibly due to the natural course of upper back pain/muscle spasm, which is generally a self-limiting disorder such that patients may have recovered at day 7 . This suggests that future studies should focus on earlier (eg, day 4) outcomes.

The directional change in effect observed for upper back/ neck/shoulder pain disability on the Vernon-Mior questionnaire end points was consistent with that of most of the other end points in the study. Subjects in the guaifenesin $1200 \mathrm{mg}$ BID group had better (lower) overall scores than subjects in the guaifenesin $600 \mathrm{mg}$ BID group, and subjects in the guaifenesin $600 \mathrm{mg}$ BID group had better (lower) scores than subjects in the placebo-1200 group. All study treatments were generally well tolerated, and no SAEs occurred.

This study adds support to the limited evidence suggesting that guaifenesin has muscle relaxant activity. ${ }^{19}$ In an earlier small, exploratory clinical study, guaifenesin at doses up to $220.5 \mathrm{mg} / \mathrm{kg}$ (100 mg/lb) of body weight showed muscle relaxant and antispasmodic effects in children with athetoid or tonic spasticity $(\mathrm{N}=18) .{ }^{19}$ Methocarbamol, a carbamate derivative of guaifenesin, also has muscle relaxant properties $^{22,23}$ and is prescribed for the relief of discomfort associated with acute, painful musculoskeletal conditions. ${ }^{24}$ Based on these prior studies, muscle spasm was selected as the primary outcome for our investigation; however, results of 
Table 4 Vernon-Mior disability index questionnaire category scores

\begin{tabular}{|c|c|c|c|c|}
\hline \multirow[t]{2}{*}{ Parameters } & \multicolumn{4}{|c|}{ Mean (SD) Vernon-Mior index score ${ }^{a}$} \\
\hline & $\begin{array}{l}\text { Guaifenesin } 600 \mathrm{mg} \text { BID } \\
(\mathrm{n}=25)\end{array}$ & $\begin{array}{l}\text { Placebo-600 } \\
(n=15)\end{array}$ & $\begin{array}{l}\text { Guaifenesin } 1200 \mathrm{mg} \text { BID } \\
(\mathrm{n}=24)\end{array}$ & $\begin{array}{l}\text { Placebo- } 1200 \\
(n=13)\end{array}$ \\
\hline \multicolumn{5}{|l|}{ Baseline } \\
\hline Pain & $3.88(0.78)$ & $3.67(0.82)$ & $3.25(0.90)$ & $3.62(0.65)$ \\
\hline Personal care & $1.96(0.74)$ & $2.07(0.80)$ & $2.00(0.78)$ & $2.00(0.82)$ \\
\hline Lifting & $3.04(1.06)$ & $3.13(1.30)$ & $2.92(1.14)$ & $3.15(1.14)$ \\
\hline Reading & $3.00(1.23)$ & $2.67(0.98)$ & $2.29(1.04)$ & $2.92(1.04)$ \\
\hline Headaches & $1.72(0.98)$ & $\mathrm{I} .87(0.74)$ & $1.79(0.93)$ & $2.23(0.83)$ \\
\hline Concentration & $2.12(1.01)$ & $2.20(1.32)$ & $1.88(0.99)$ & $2.08(0.49)$ \\
\hline Work & $2.64(1.19)$ & $2.80(1.01)$ & $2.50(0.83)$ & $3.00(1.35)$ \\
\hline Driving & $3.12(1.42)$ & $2.67(0.82)$ & $2.21(0.78)$ & $3.00(1.23)$ \\
\hline Sleeping & $3.16(1.18)$ & $3.47(1.36)$ & $2.96(1.08)$ & $3.23(1.36)$ \\
\hline Recreation & $3.44(1.26)$ & $3.27(1.10)$ & $2.88(0.99)$ & $3.23(1.24)$ \\
\hline \multicolumn{5}{|l|}{ Day 4} \\
\hline Pain & $2.72(0.98)$ & $2.53(0.83)$ & $2.29(0.96)$ & $2.83(0.58)$ \\
\hline Personal care & $1.72(0.68)$ & $1.60(0.63)$ & $\mathrm{I} .50(0.5 \mathrm{I})$ & $1.75(0.75)$ \\
\hline Lifting & $2.80(1.26)$ & $2.27(1.10)$ & $2.58(1.14)$ & $2.42(1.3 \mathrm{I})$ \\
\hline Reading & $2.40(0.91)$ & $2.20(1.01)$ & $1.88(0.95)$ & $2.38(0.65)$ \\
\hline Headaches & $1.76(1.17)$ & $1.67(0.90)$ & $2.04(1.37)$ & $2.23(0.83)$ \\
\hline Concentration & $1.75(0.74)$ & $1.60(0.5 \mathrm{I})$ & I.54 (0.59) & $2.00(0.7 I)$ \\
\hline Work & $2.20(0.96)$ & $2.13(0.92)$ & $1.92(0.93)$ & $2.46(0.88)$ \\
\hline Driving & $2.56(1.53)$ & $2.13(1.30)$ & $1.79(0.78)$ & 2.38 (1.19) \\
\hline Sleeping & $2.76(1.36)$ & 2.67 (I.29) & $2.42(1.14)$ & $2.92(1.19)$ \\
\hline Recreation & $2.44(1.12)$ & $2.40(1.12)$ & $2.17(0.92)$ & $2.54(1.27)$ \\
\hline \multicolumn{5}{|l|}{ Day 7} \\
\hline Pain & $2.48(0.92)$ & $2.20(0.86)$ & $1.88(0.80)$ & $1.92(0.64)$ \\
\hline Personal care & $\mathrm{I} .60(0.7 \mathrm{I})$ & $1.33(0.49)$ & $1.29(0.55)$ & $1.46(0.52)$ \\
\hline Lifting & $2.56(1.39)$ & $2.00(1.31)$ & $2.04(1.00)$ & $2.00(1.29)$ \\
\hline Reading & $2.00(0.7 I)$ & $1.73(0.80)$ & $1.58(0.78)$ & $1.85(0.69)$ \\
\hline Headaches & $1.60(0.91)$ & $1.67(0.62)$ & $1.75(1.15)$ & $2.00(0.82)$ \\
\hline Concentration & $1.76(0.83)$ & $1.53(0.64)$ & I.46 (0.59) & $\mathrm{I} .62(0.5 \mathrm{I})$ \\
\hline Work & $1.96(0.84)$ & $1.73(0.80)$ & $1.75(0.85)$ & $2.08(1.38)$ \\
\hline Driving & $2.48(1.50)$ & $2.00(1.25)$ & $\mathrm{I} .46(0.5 \mathrm{I})$ & $2.15(1.35)$ \\
\hline Sleeping & $2.56(1.19)$ & $2.20(0.86)$ & $2.04(1.08)$ & $1.92(0.95)$ \\
\hline Recreation & $2.29(1.08)$ & $1.73(0.59)$ & $1.88(1.04)$ & $2.08(1.32)$ \\
\hline
\end{tabular}

Notes: ${ }^{a}$ Vernon-Mior questionnaire components measured by upper back/neck/shoulder score for pain intensity, personal care, lifting, reading, headaches, concentration, work, driving, sleeping, and recreation. Each of these components was assessed at baseline and at days 4 and 7 based on a scale of I-6, with I representing no disability and 6 representing complete disability. Values in table represent mean (SD) score for each Vernon-Mior component by treatment group. BID, twice daily; placebo-600, placebo matched to guaifenesin $600 \mathrm{mg}$ BID; placebo-1200, placebo matched to guaifenesin I $200 \mathrm{mg}$ BID.

Abbreviation: SD, standard deviation.

the secondary end points showed the largest treatment effect for guaifenesin $1200 \mathrm{mg}$ BID vs placebo- 1200 on muscle pain and discomfort. Therefore, pain and discomfort may be more appropriate primary end points in future studies.

Acute, non-traumatic back, shoulder, and neck pain may be self-limiting and, for most patients, may improve or resolve within several days of onset without intervention; however, the pain sometimes persists or recurs and converts to a chronic condition lasting months or even years. ${ }^{25-27}$ The availability of an OTC muscle relaxant may provide timely access to an effective remedy for relief of acute symptoms.

While none of the directional changes in effect observed in the primary and secondary outcomes achieved statistical significance, it should be noted that this was a small, proof-of-principle study for which sample size was not powered to show statistical difference between active treatments and their matched placebos. Furthermore, the 2:2:1:1 randomization ratio led to only 15 subjects assigned to placebo-600 and 14 assigned to placebo-1200; the small numbers of subjects may have contributed to the higher than expected placebo response in the placebo-600 group due to sampling bias and the possibility that the subjects were not representative of the general population experiencing upper back, neck, and shoulder pain. Nonetheless, this study has provided interesting preliminary evidence on another potential therapeutic use for OTC guaifenesin. Therefore, a larger, adequately powered study is warranted to further investigate the potential muscle relaxant and pain reduction effects of guaifenesin $1200 \mathrm{mg}$ BID. 


\section{Conclusion}

Results from this proof-of-principle study showed a directional change in benefit from placebo to lower and upper doses of guaifenesin for muscle spasm, pain, tension, discomfort, and relaxation, suggesting that the OTC dose of guaifenesin $1200 \mathrm{mg}$ BID may potentially provide symptom relief from upper back, neck, and shoulder musculoskeletal pain and discomfort. Treatment with guaifenesin $1200 \mathrm{mg}$ BID was generally well tolerated. Larger, adequately powered robust studies are needed to confirm these preliminary findings.

\section{Acknowledgments}

This study was sponsored by GlaxoSmithKline Consumer Healthcare. Medical writing assistance was provided by Peloton Advantage and was funded by GlaxoSmithKline Consumer Healthcare.

\section{Disclosure}

Kenneth Reed is an employee of GlaxoSmithKline Consumer Healthcare. Dr Agron Collaku and Dr Yong Yue were employees of GlaxoSmithKline Consumer Healthcare at the time of this study. The authors report no other conflicts of interest in this work.

\section{References}

1. Bernard BP, Putz-Anderson V, Burt SE, et al. Musculoskeletal Disorders and Workplace Factors - A Critical Review of Epidemiologic Evidence for Work-Related Musculoskeletal Disorders of the Neck, Upper Extremity, and Low Back. Cincinnati, OH: National Institute for Occupational Safety and Health; 1997.

2. Park SY, Yoo WG. Effect of sustained typing work on changes in scapular position, pressure pain sensitivity and upper trapezius activity. JOccup Health. 2013;55(3):167-172.

3. Occhionero V, Korpinen L, Gobba F. Upper limb musculoskeletal disorders in healthcare personnel. Ergonomics. 2014;57(8):1166-1191.

4. Linaker CH, Walker-Bone K. Shoulder disorders and occupation. Best Pract Res Clin Rheumatol. 2015;29(3):405-423.

5. de Looze M, Bosch T, van Dieen J. Manifestations of shoulder fatigue in prolonged activities involving low-force contractions. Ergonomics. 2009;52(4):428-437.

6. United States Department of Labor [webpage on the Internet]. Prevention of work-related musculoskeletal disorders; 2014. Available at: https:/www.osha.gov/pls/oshaweb/owadisp.show_document?p_ table=UNIFIED_AGENDA\&p_id=4481. Accessed January 17, 2017.

7. Pejcic N, Duric-Jovicic M, Miljkovic N, Popovic DB, Petrovic V. Posture in dentists: sitting vs. standing positions during dentistry work - an EMG study. Srp Arh Celok Lek. 2016;144(3-4):181-187.

8. Lee ST, Moon J, Lee SH, et al. Changes in activation of serratus anterior, trapezius and latissimus dorsi with slouched posture. Ann Rehabil Med. 2016;40(2):318-325.
9. Waersted M, Hanvold TN, Veiersted KB. Computer work and musculoskeletal disorders of the neck and upper extremity: a systematic review. BMC Musculoskelet Disord. 2010;11:79.

10. Roquelaure Y, Ha C, Rouillon C, et al. Risk factors for upper-extremity musculoskeletal disorders in the working population. Arthritis Rheum. 2009;61(10):1425-1434.

11. Hanvold TN, Veiersted KB, Waersted M. A prospective study of neck, shoulder, and upper back pain among technical school students entering working life. J Adolesc Health. 2010;46(5):488-494.

12. Long MH, Bogossian FE, Johnston V. The prevalence of work-related neck, shoulder, and upper back musculoskeletal disorders among midwives, nurses, and physicians: a systematic review. Workplace Health Saf. 2013;61(5):223-229. quiz 230.

13. Van Eerd D, Munhall C, Irvin E, et al. Effectiveness of workplace interventions in the prevention of upper extremity musculoskeletal disorders and symptoms: an update of the evidence. Occup Environ Med. 2016;73(1):62-70.

14. Ndlovu M, Bedson J, Jones PW, Jordan KP. Pain medication management of musculoskeletal conditions at first presentation in primary care: analysis of routinely collected medical record data. BMC Musculoskelet Disord. 2014;15:418.

15. Hunt RH, Choquette D, Craig BN, et al. Approach to managing musculoskeletal pain: acetaminophen, cyclooxygenase-2 inhibitors, or traditional NSAIDs? Can Fam Physician. 2007;53(7): 1177-1184.

16. Childers MK, Borenstein D, Brown RL, et al. Low-dose cyclobenzaprine versus combination therapy with ibuprofen for acute neck or back pain with muscle spasm: a randomized trial. Curr Med Res Opin. 2005;21(9):1485-1493.

17. Chou R, Peterson K, Helfand M. Comparative efficacy and safety of skeletal muscle relaxants for spasticity and musculoskeletal conditions: a systematic review. J Pain Symptom Manage. 2004;28(2): $140-175$.

18. Keshavarz M, Showraki A, Emamghoreishi M. Anticonvulsant effect of Guaifenesin against pentylenetetrazol-induced seizure in mice. Iran J Med Sci. 2013;38(2):116-121.

19. Carter $\mathrm{CH}$. Muscle relaxant properties of glyceryl guaiacolate. West Med Med J West. 1966;7(8):206-211.

20. Sofia RD. Effect of glyceryl guaiacolate in animal models of inflammation and pain. Res Commun Chem Pathol Pharmacol. 1980;28(2): 285-293.

21. Pralong E, Millar JD, Lodge D. Specificity and potency of N-methyl-Daspartate glycine site antagonists and of mephenesin on the rat spinal cord in vitro. Neurosci Lett. 1992;136(1):56-58.

22. Carpenter EB. Methocarbamol as a muscle relaxant: its clinical evaluation in acute trauma and chronic neurological states. South Med J. 1958;51(5):627-630.

23. Valtonen EJ. A double-blind trial of methocarbamol versus placebo in painful muscle spasm. Curr Med Res Opin. 1975;3(6):382-385.

24. Robaxin [package insert]. Lake Forest, IL: Actient Pharmaceuticals; 2011.

25. Binder AI. Neck pain. BMJ Clin Evid. 2008;2008:pii:1103.

26. Pernold G, Mortimer M, Wiktorin C, Tornqvist EW, Vingard E; Musculoskeletal Intervention Center-Norrtälje Study Group. Neck/ shoulder disorders in a general population. Natural course and influence of physical exercise: a 5-year follow-up. Spine (Phila Pa 1976). 2005;30(13):E363-E368.

27. Vasseljen O, Woodhouse A, Bjorngaard JH, Leivseth L. Natural course of acute neck and low back pain in the general population: the HUNT study. Pain. 2013;154(8):1237-1244. 


\section{Supplementary material}

Table SI GASD, GAHF, and GAHI at day 7 (ITT population)

\begin{tabular}{|c|c|c|c|c|}
\hline Parameters & $\begin{array}{l}\text { Guaifenesin } 600 \mathrm{mg} \text { BID } \\
(n=25)\end{array}$ & $\begin{array}{l}\text { Placebo-600 } \\
(n=15)\end{array}$ & $\begin{array}{l}\text { Guaifenesin } 1200 \mathrm{mg} \text { BID } \\
(\mathrm{n}=24)\end{array}$ & $\begin{array}{l}\text { Placebo- } 1200 \\
(n=13)\end{array}$ \\
\hline \multicolumn{5}{|l|}{ GASD, n (\%) } \\
\hline Decreased & $8(32.0)$ & $8(53.3)$ & $10(4 \mid .7)$ & $7(53.9)$ \\
\hline Increased & I (4.0) & 0 & $2(8.3)$ & I (7.7) \\
\hline Stayed the same & $16(64.0)$ & 7 (46.7) & $12(50.0)$ & $5(38.5)$ \\
\hline \multicolumn{5}{|l|}{ GAHF, n (\%) } \\
\hline Decreased & $9(36.0)$ & $9(60.0)$ & 7 (29.2) & $4(30.8)$ \\
\hline Increased & $3(12.0)$ & 0 & I (4.2) & 0 \\
\hline Stayed the same & $13(52.0)$ & $6(40.0)$ & $16(66.7)$ & $9(69.2)$ \\
\hline \multicolumn{5}{|l|}{ GAHI, n (\%) } \\
\hline Decreased & $10(40.0)$ & $9(60.0)$ & $9(37.5)$ & $4(30.8)$ \\
\hline Increased & I (4.0) & 0 & I (4.2) & 0 \\
\hline Stayed the same & $14(56.0)$ & $6(40.0)$ & $14(58.3)$ & $9(69.2)$ \\
\hline
\end{tabular}

Notes: BID, twice daily; placebo-600, placebo matched to guaifenesin $600 \mathrm{mg}$ BID; placebo- 1200, placebo matched to guaifenesin I $200 \mathrm{mg}$ BID.

Abbreviations: GASD, global assessment of sleep disturbance; GAHF, global assessment of headache frequency; GAHI, global assessment of headache intensity; ITT, intent-to-treat.

\section{Publish your work in this journal}

The Journal of Pain Research is an international, peer reviewed, open access, online journal that welcomes laboratory and clinical findings in the fields of pain research and the prevention and management of pain. Original research, reviews, symposium reports, hypothesis formation and commentaries are all considered for publication.

\section{Dovepress}

The manuscript management system is completely online and includes a very quick and fair peer-review system, which is all easy to use. Visit http://www.dovepress.com/testimonials.php to read real quotes from published authors. 